\title{
Identification of differentially expressed genes in MG63 osteosarcoma cells with drug-resistance by microarray analysis
}

\author{
RUI CHEN ${ }^{1}$, LI-HONG HUANG ${ }^{2}$, YI-YAO GAO $^{3}$, JIAN-ZENG YANG ${ }^{4}$ and YAN WANG ${ }^{3}$ \\ ${ }^{1}$ Department of Nuclear Medicine; Changhai Hospital of Shanghai, Shanghai 200433; ${ }^{2}$ Geriatric Department; \\ ${ }^{3}$ Science Research Center, China-Japan Union Hospital of Jilin University, Changchun, Jilin 130033; \\ ${ }^{4}$ Henan Medical Key Laboratory of Molecular Imaging, Nuclear Medicine Department, \\ The First Affiliated Hospital of Zhengzhou University, Zhengzhou, Henan 450000, P.R. China
}

Received March 26, 2018; Accepted November 9, 2018

DOI: $10.3892 / \mathrm{mmr} .2018 .9774$

\begin{abstract}
Osteosarcoma is the most common type of primary malignant bone tumor, with extremely poor prognosis in patients withmetastatic disease and resistance to therapy, such as multidrug regimens. The mechanisms of drug resistance are quite complex and have not been fully elucidated; thus, novel therapeutic targets should be identified to alleviate drug resistance in osteosarcoma. In the present study, the transcriptomes of the human osteosarcoma cell line MG63 and vincristine (VCR)-resistant MG63 cells were compared by microarray analysis. A total of 1,300 genes (602 upregulated and 698 downregulated) were reported to be differentially expressed in MG63/VCR compared with MG63 cells. Bioinformatics analysis predicted that the differentially expressed genes were mainly enriched in the B cell receptor, UVA-induced mitogen-activated protein kinases and receptor tyrosine kinase 2/3 signaling pathways. In the present study, 10 of the dysregulated genes, including roundabout homolog 1, death-associated protein kinase 1 and A-kinase anchor protein 12 were further evaluated by reverse transcription-quantitative polymerase chain reaction. These results may aid the validation of candidate biomarkers for the treatment and prognosis of osteosarcoma, and provide novel insight into the molecular mechanisms underlying the drug resistance of osteosarcoma cells.
\end{abstract}

\section{Introduction}

Osteosarcoma is the most common type of primary malignant bone tumor with a high rate of metastasis (1). Furthermore, few biomarkers have been reported for early detection and differential diagnosis; the aggressiveness of osteosarcoma with rapid metastatic potential contributes to the poor prognosis of

Correspondence to: Professor Yan Wang, Science Research Center, China-Japan Union Hospital of Jilin University, 126 Xiantai Street, Changchun, Jilin 130033, P.R. China

E-mail: wangy01@jlu.edu.cn

Key words: osteosarcoma, drug resistance, microarray analysis patients with the metastatic form of this disease (2,3). Multidrug regimens are used to control tumor cells at various stages of the cell cycle, eliminate local or distant micrometastases, and reduce the emergence of drug-resistant cells, which prolongs the overall and progression-free survival of patients with osteosarcoma compared with single-drug treatments, such as vincristine (VCR) $(4,5)$. However, $\leq 40 \%$ of all human cancers develop multidrug resistance (MDR) following an initial period of response to treatment, and $\sim 30 \%$ of osteosarcoma patients with MDR exhibit recurrence or metastasis during a five-year period (6-8). The mechanisms of drug resistance are multifactorial, including disruption of transporter pumps, oncogenes, tumor suppressor genes, DNA repair system, mitochondrial alterations, autophagy and epithelial-mesenchymal transition $(9,10)$; however, the mechanisms underlying drug resistance are complex and require further investigation. Therefore, the associated molecular mechanisms and biomarkers should be identified.

The aim of the present study was to analyze the gene expression profiles of the human osteosarcoma cell line MG63 compared with VCR-resistant MG63 cells (MG63/VCR). These results may provide novel insight into identifying chemotherapeutic targets and developing more effective chemotherapy strategies for the treatment of osteosarcoma with VCR resistance.

\section{Materials and methods}

Cell culture. The human VCR-resistant osteosarcoma cell line MG63/VCR and its parental cell line MG63 were obtained from the Scientific Research Center, China-Japan Union Hospital of Jilin University (Jilin, China) (11). The cells were cultured in high-glucose Dulbecco's modified Eagle's medium (H-DMEM; Invitrogen, Thermo Fisher Scientific, Inc., Waltham, MA, USA) supplemented with $10 \%$ fetal bovine serum (FBS; HyClone; GE Healthcare Life Sciences, Logan, UT, USA) in a humidified atmosphere with $5 \% \mathrm{CO}_{2}$ at $37^{\circ} \mathrm{C}$; three biological replicates were conducted using the MG63 and MG63/VCR cells.

Cell viability assay. The cells were suspended at a density of $8 \times 10^{3}$ cells per well and plated into 96-well plates in $100 \mu \mathrm{l}$ H-DMEM supplemented with $10 \%$ FBS. Following incubation at $37^{\circ} \mathrm{C}$ for $24 \mathrm{~h}$, the cells were treated with VCR (New Hualian Pharmaceutical Co., Shanghai, China) at the following 
final concentrations: $2,000,1,000,500,250,125$, and $62.5 \mathrm{ng} / \mathrm{ml}$; drug-free medium was used as the control. MG63 cells were treated with the following concentrations: 64,16 , $4,1,0.25$ and $0.0625 \mathrm{ng} / \mathrm{ml}$. The half-maximal inhibitory concentration $\left(\mathrm{IC}_{50}\right.$ ) of VCR in MG63/VCR and MG63 cells was reported to be 453.4 and $0.952 \mathrm{ng} / \mathrm{ml}$, respectively (11). A total of two groups of cells continued to culture $48 \mathrm{~h}$ in drug medium at $37^{\circ} \mathrm{C}$. Cell viability was examined using $10 \%$ Cell Counting kit-8 (CCK-8; Dojindo Molecular Technologies, Inc., Kumamoto, Japan) according to the manufacturer's protocols, and the cells were incubated at $37^{\circ} \mathrm{C}$ for another $2 \mathrm{~h}$. Subsequently, the optical density (OD) was determined by measuring the absorbance at $450 \mathrm{~nm}$ using a plate reader (UV8100D; LabTech, Inc., Hopkinton, MA, USA), and the inhibition ratio was calculated using the following formula: Inhibition ratio $=\left[\left(\mathrm{OD}_{\text {control }}-\mathrm{OD}_{\text {experiment }}\right) / \mathrm{OD}_{\text {control }}\right] \times 100 \%$. Each experiment was performed in triplicate.

Total RNA extraction and microarray. Total RNA was extracted from the MG63/VCR and MG63 cells using TRIzol ${ }^{\mathbb{B}}$ reagent (Invitrogen; Thermo Fisher Scientific, Inc.). The quality of total RNA was determined using a NanoDrop 2000 spectrophotometer $(1.7<\mathrm{A} 260 / \mathrm{A} 280<2.2)$ and the RNA integrity (RIN) was evaluated using an Agilent Bioanalyzer 2100 ( $\mathrm{RIN} \geq 7.0$ and $28 \mathrm{~S} / 18 \mathrm{~S}>0.7$ ). The initial amount of total RNA (300-500 ng) was further amplified, labeled and purified by using the Microarray GeneChip 3'IVT Express kit (Affymetrix; Thermo Fisher Scientific, Inc.) According to the standard hybridization procedures and matching kit provided by Affymetrix expression chip. RNA was then subjected to treatment with the GeneChip Hybridization, Wash, and Stain kit reagent (Affymetrix; Thermo Fisher Scientific, Inc.), Rolling hybridization in a Hybridization Oven 645 for $45^{\circ} \mathrm{C}, 16 \mathrm{~h}$, and washed in GeneChip Fluidics Station 450 (Affymetrix; Thermo Fisher Scientific, Inc.) according to the manufacturer's protocols. The results of the chip were scanned with a GeneChip Scanner 3000 system (Affymetrix; Thermo Fisher Scientific, Inc.). Differentially expressed genes in the two cell lines were determined using the fold change (FC) values. The gene expression profile was presented in Excel spreadsheets (Microsoft Corporation, Redmond, WA, USA). Volcano plot, Scatter-plot and Clustergram were used to analyze the differential gene expression. Gene set enrichment analysis was performed using Ingenuity Pathway Analysis (IPA) online software $(12,13)$.

Reverse transcription-quantitative polymerase chain reaction (RT-qPCR). Total RNA was extracted from the MG63/VCR and MG63 cells using TRIzol ${ }^{\circledR}$ reagent and reverse-transcribed into cDNA using RevertAid First Strand cDNA Synthesis kit (both Invitrogen; Thermo Fisher Scientific, Inc.) according to the manufacturer's protocols. The primers used for RT-qPCR were listed in Table I. qPCR was performed using SYBR ${ }^{\circledR}$ Premix Ex Taq ${ }^{\mathrm{TM}}$ II (Takara Biotechnology Co., Ltd., Dalian, China) on the Applied Biosystems 7500 Fast Real-Time PCR system (Applied Biosystems; Thermo Fisher Scientific, Inc.). The conditions used for qPCR were as follows: Denaturation at $95^{\circ} \mathrm{C}$ for $30 \mathrm{sec}$; annealing at $58-62^{\circ} \mathrm{C}$ for $30 \mathrm{sec}$; and 30 cycles of elongation at $95^{\circ} \mathrm{C}$ for $15 \mathrm{sec}, 60^{\circ} \mathrm{C}$ for $30 \mathrm{sec}$, and $95^{\circ} \mathrm{C}$ for $15 \mathrm{sec}$. The relative expression levels of each gene, normalized

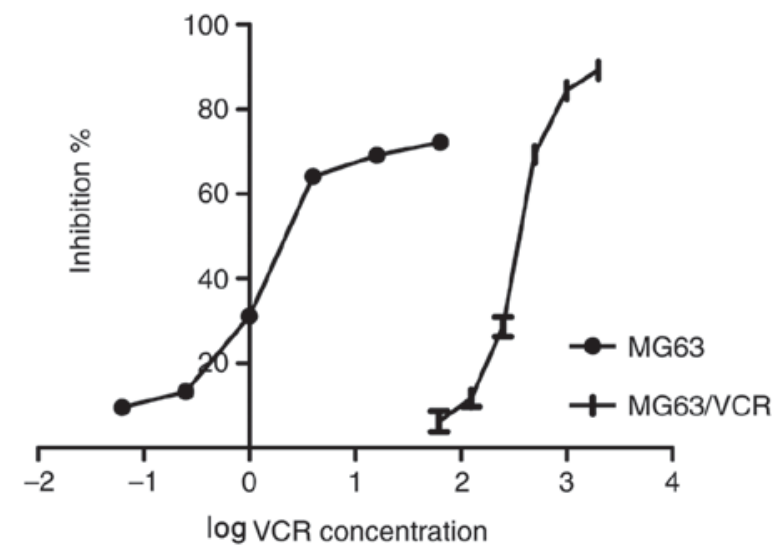

Figure 1. Effects of VCR on cell survival. The half-maximal inhibitory concentration at which VCR exhibited $50 \%$ inhibition on the viability of MG63 and MG63/VCR cells was determined with GraphPad Prism software using global nonlinear regression analysis. The X-axis represented $\log$ (VCR concentration), and the $\mathrm{Y}$-axis indicated the inhibition ratio. VCR, vincristine.

to the housekeeping gene $G A P D H$, was calculated using the $2^{-\Delta \Delta C q}$ method (14).

Statistical analysis. Statistical analyses were performed using GraphPad Prism 5 (GraphPad Software, Inc., La Jolla, CA, USA), and all data are presented as the mean \pm standard deviation. The statistical significance of the differences between the cell lines and treatments was analyzed by a Student's test or one-way analysis of variance and Tukey's test. $\mathrm{IC}_{50}$ was performed using global nonlinear regression analysis. Differential gene expression analysis was performed using a Student's t-test. The result of the chip analysis is the weighted average of repeated probe signals in each group. The threshold for statistical significance was $\mathrm{P}<0.05, \mid \mathrm{FCl}>1.5$. To systematically assign putative functions to the differentially expressed genes, bioinformatics analysis was performed with IPA. The unique statistical index of IPA is the z-score, which represents the direction and multiplier of the molecular changes under the existing experimental conditions. The z-score indicates whether the results are consistent with the references mentioned in the literature; inhibition or activation of the molecular action process was considered when $|z|>2$. A positive $z$-score suggests that the molecular interaction is activated, whereas a negative $\mathrm{z}$-score indicates that the molecular interaction is inhibited.

\section{Results}

Sensitivity of MG63/VCR and MG63 cells to vincristine. To investigate the chemosensitivity of MG63/VCR and MG63 cells to VCR, the $\mathrm{IC}_{50}$ values in response to treatment with different VCR concentrations were determined. Following $48 \mathrm{~h}$ of culture in a VCR-containing medium, the IC50 value for MG63/VCR cells was significantly increased compared with that of MG63 cells $(493.175 \pm 4.473$ vs. $1.407 \pm 0.111 \mathrm{ng} / \mathrm{ml}$, $\mathrm{P}=0.001$ ), suggesting that MG63/VCR cells are more refractory to VCR compared with the parental MG63 cell line (Fig. 1).

Distinct gene expression landscapes between MG63/VCR and MG63 cells. In total, the genes that exhibited significantly aberrant expression between the two cell lines in 
Table I. Primers used for reverse transcription-quantitative polymerase chain reaction.

\begin{tabular}{|c|c|c|}
\hline Gene & Forward (5'-3') & Reverse (5'-3') \\
\hline GAPDH & GCACCGTCAAGGCTGAGAAC & TGGTGAAGACGCCAGTGGA \\
\hline$M D R 1$ & ATATCAGCAGCCCACATCAT & GAAGCACTGGGATGTCCGGT \\
\hline$I G F 2 B P 1$ & CCACCAGTTGGAGAACCATGCC & ATGTCCACTTGCTGCTGCTTGG \\
\hline TES & GCATGATGTCCTCTTGAGCAATGAAG & CATTCTTCTTGGCAGCAACTGGATTC \\
\hline CAII & CTGAGCACTGGCATAAGGACTTCC & ATACTTGGCTGTATGAGTGTCGATGTC \\
\hline$A K A P 12$ & CTCCACCGAGCAGCGCAG & GGTCCGAGGCAGCGATGG \\
\hline COL1A2 & TGTGATTTCTCTACTGGCGAAACC & ACGTGTTTCTTGTCCTTGGAGC \\
\hline $\mathrm{ROBO1}$ & ACCCAGTAACTTGGCAGTAACTGT & TGGGCAGCTCTCCATCATCT \\
\hline$D A P K 1$ & AGCACCGGCCTCCAGTATGC & TGTCCTCGCGGCTCACACC \\
\hline SLIT2 & TTAACTGTAACTGCTACCTGGCTTGG & TCATCACAAGTGAAGTCCTGAATGGC \\
\hline FLRT3 & GCTGTTCCTTCAAGTAGCACCTCTATC & TTGTAGCATCCTCTGGTATTCCTGTTG \\
\hline
\end{tabular}

MDR1, multi-drug resistance gene 1; IGF2BP1, insulin-like growth factor-II binding protein 1; TES, testin LIM domain protein; CAII, carbonic anhydrase II; AKAP12, A-kinase anchor protein 12; COL1A2, collagen A2; ROBO1, roundabout homolog 1; DAPK1, death-associated protein kinase 1; SLIT2, slit guidance ligand 2; FLRT3, fibronectin leucine rich transmembrane protein 3.

A

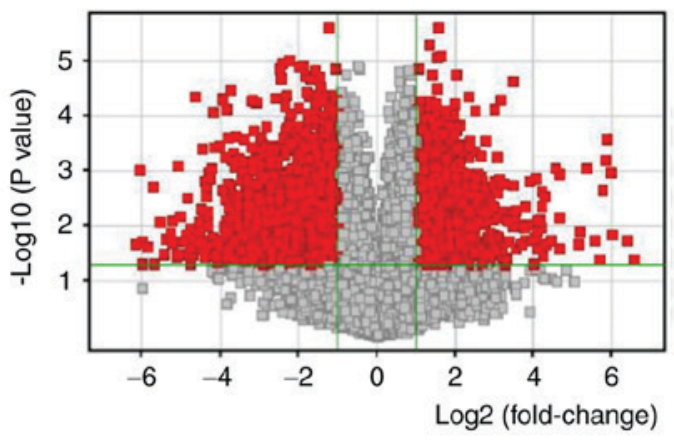

B

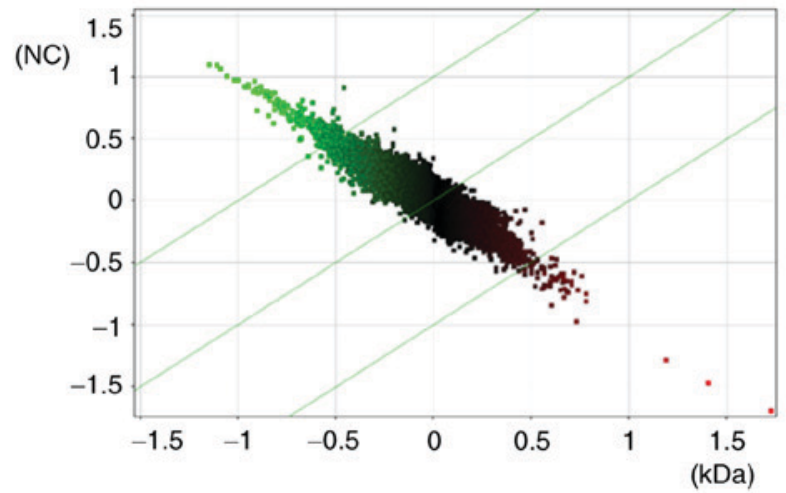

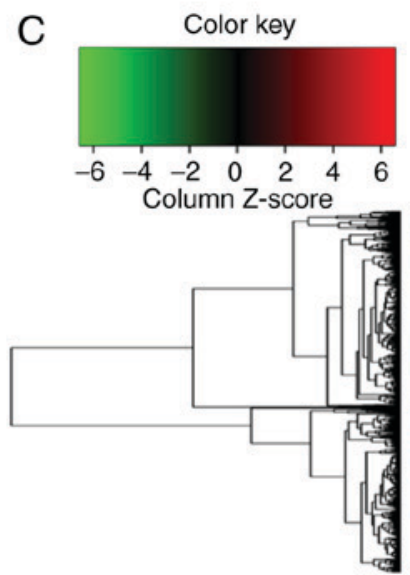

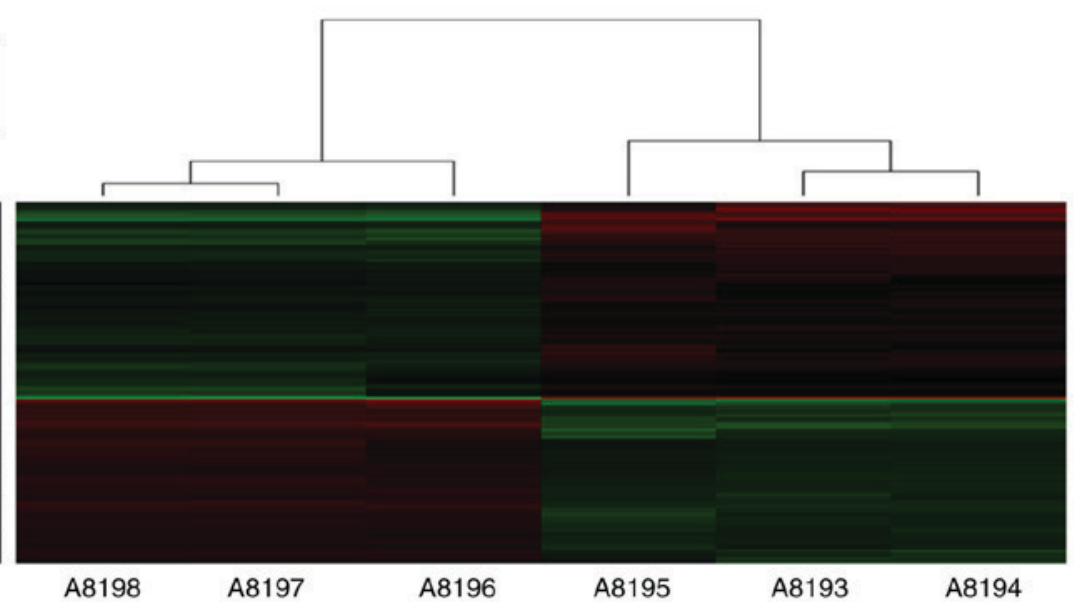

Figure 2. Differentially expressed genes in MG63/VCR and MG63 cells based on microarray analysis. (A) Volcano plot: The X-axis represented the fold change values $\left(\log _{2}\right.$-scaled), and the Y-axis indicated the corrected P-values ( $\log _{10}$-scaled); the red dots represented differentially expressed genes with statistical significance. (B) Scatter-plot: The X-axis represented the data of the control group and the Y-axis indicated the data of the experimental groups. The data above or below the highest green line indicated that the probe was downregulated or upregulated, respectively, in MG63/VCR cells compared with MG63 cells. (C) Clustergram: Each row and column represented a gene and sample, respectively. A8193, A8194 and A8195 represented the three samples of MG63 cells; A8196, A8197 and A8198 represented the three samples of MG63/VCR cells. Red indicates upregulated gene expression and green indicates downregulated gene expression.

microarray analysis were evaluated by volcano plot filtering $(\mathrm{P}<0.05, \mathrm{FC} \geq 1.5$; Fig. 2A). A total of 602 genes were upregulated and 698 were downregulated in MG63/VCR cells compared with MG63 cells. The scatterplot and cluster 
Table II. Genes with downregulated expression in MG63/VCR relative to MG63 cells.

\begin{tabular}{|c|c|c|c|c|}
\hline Gene & Gene name & P-value & Fold change & False discover \\
\hline \multicolumn{5}{|c|}{ Transcription factors } \\
\hline TP63 & Tumor protein 63 & 0.00092 & -7.26360 & 0.00266 \\
\hline$Z E B 2$ & Zinc finger E-box binding homeobox 2 & 0.00016 & -4.23951 & 0.00145 \\
\hline \multicolumn{5}{|l|}{ Transporters } \\
\hline$F A B P 5$ & $\begin{array}{l}\text { Fatty acid binding protein } 5 \\
\text { (psoriasis-associated) }\end{array}$ & $<0.00001$ & -66.32220 & 0.00035 \\
\hline$A B C A 8$ & $\begin{array}{l}\text { ATP-binding cassette, sub-family A } \\
(\mathrm{ABC} 1), \text { member } 8\end{array}$ & 0.00055 & -4.11858 & 0.00220 \\
\hline \multicolumn{5}{|c|}{ Transmembrane receptors } \\
\hline IL13RA2 & Interleukin 13 receptor, a2 & 0.00008 & -15.08010 & 0.00111 \\
\hline \multicolumn{5}{|l|}{ Enzymes } \\
\hline PLSCR4 & Phospholipase scramblase 2 & 0.00226 & -5.89258 & 0.00442 \\
\hline CHI3L1 & Chitinase 3-like 1 (cartilage glycoprotein-39) & $<0.00001$ & -196.98900 & 0.00061 \\
\hline TGM2 & Transglutaminase 2 & 0.00006 & -4.85356 & 0.00106 \\
\hline EFEMP1 & $\begin{array}{l}\text { EGF containing fibulin-like extracellular } \\
\text { matrix protein } 1\end{array}$ & 0.00011 & -5.37078 & 0.00124 \\
\hline MSMO1 & Methylsterol monooxygenase 1 & 0.00232 & -8.35006 & 0.00449 \\
\hline$L O X$ & Lysyl oxidase & 0.00035 & -4.77463 & 0.00180 \\
\hline$A K R I C 3$ & $\begin{array}{l}\text { Aldo-keto reductase family } 1 \text {, } \\
\text { member C3 }\end{array}$ & 0.00009 & -6.83914 & 0.00116 \\
\hline \multicolumn{5}{|l|}{ Other } \\
\hline IL15 & Interleukin 15 & 0.00427 & -4.77006 & 0.00698 \\
\hline CCL2 & Chemokine (C-C motif) ligand 2 & 0.00107 & -7.26246 & 0.00288 \\
\hline$K C N K 2$ & $\begin{array}{l}\text { Potassium channel, two pore } \\
\text { domain subfamily } \mathrm{K} \text {, member } 2\end{array}$ & 0.00017 & -5.20959 & 0.00146 \\
\hline KCNJ2 & $\begin{array}{l}\text { Potassium channel, inwardly } \\
\text { rectifying subfamily } \mathrm{J} \text {, member } 2\end{array}$ & 0.00017 & -4.15907 & 0.00146 \\
\hline$D A P K 1$ & Death-associated protein kinase 1 & 0.00072 & -5.37922 & 0.00242 \\
\hline$D K K 1$ & Dickkopf WNT signaling pathway inhibitor 1 & 0.00007 & -6.61779 & 0.00109 \\
\hline GSAP & $\gamma$-secretase activating protein & 0.00104 & -4.12709 & 0.00283 \\
\hline ADAMTS1 & $\begin{array}{l}\text { ADAM metallopeptidase with } \\
\text { thrombospondin type } 1 \text { motif, } 1\end{array}$ & $<0.00001$ & -4.76113 & 0.00058 \\
\hline SLIT2 & Slit guidance ligand 2 & 0.00037 & -8.33081 & 0.00186 \\
\hline THBS2 & Thrombospondin 2 & $<0.00001$ & -4.12890 & 0.00047 \\
\hline$C C D C 102 B$ & Coiled-coil domain containing 102B & 0.00063 & -6.34919 & 0.00230 \\
\hline $\mathrm{CDH} 2$ & Cadherin 2, type $1, \mathrm{~N}$-cadherin (neuronal) & $<0.00001$ & -8.36960 & 0.00045 \\
\hline TM4SF 18 & Transmembrane 4 L six family member 18 & 0.00016 & -6.42868 & 0.00145 \\
\hline FLRT3 & $\begin{array}{l}\text { Fibronectin leucine rich transmembrane } \\
\text { protein } 3\end{array}$ & 0.00057 & -5.87903 & 0.00224 \\
\hline THY1 & Thy- 1 cell surface antigen & $<0.00001$ & -18.64350 & 0.00046 \\
\hline SHISA3 & Shisa family member 3 & $<0.00001$ & -8.51613 & 0.00035 \\
\hline$I T G B 8$ & Integrin, b8 & 0.00578 & -4.32276 & 0.00873 \\
\hline CDH11 & Cadherin 11 , type 2, OB-cadherin (osteoblast) & 0.00001 & -8.02862 & 0.00065 \\
\hline COL3A1 & Collagen, type III, a1 & 0.00011 & -11.94630 & 0.00124 \\
\hline PCDH18 & Protocadherin 18 & 0.00109 & -4.42683 & 0.00290 \\
\hline $\mathrm{LRCH} 2$ & $\begin{array}{l}\text { Leucine-rich repeats and calponin homology } \\
(\mathrm{CH}) \text { domain containing } 2\end{array}$ & 0.00129 & -5.18966 & 0.00321 \\
\hline SEMA6D & $\begin{array}{l}\text { Sema domain, transmembrane domain (TM), } \\
\text { and cytoplasmic domain, (semaphorin) 6D }\end{array}$ & 0.00004 & -4.88122 & 0.00096 \\
\hline TES & Testin LIM domain protein & 0.00015 & -22.05530 & 0.00139 \\
\hline LUM & Lumican & 0.00582 & -4.02085 & 0.00877 \\
\hline SPRY1 & Sprouty RTK signaling antagonist 1 & 0.00009 & -6.06186 & 0.00116 \\
\hline
\end{tabular}


Table II. Continued.

\begin{tabular}{|c|c|c|c|c|}
\hline Gene & Gene name & P-value & Fold change & False discovery rate \\
\hline \multicolumn{5}{|l|}{ Other } \\
\hline$C D 46$ & CD46 molecule, complement regulatory protein & 0.01614 & -4.36522 & 0.01969 \\
\hline CCNG1 & Cyclin G1 & 0.00188 & -6.89583 & 0.00396 \\
\hline$A B I 3 B P$ & $\begin{array}{l}\text { ABI family, member } 3 \text { (NESH) } \\
\text { binding protein }\end{array}$ & 0.00005 & -6.61567 & 0.00106 \\
\hline$F L R T 2$ & $\begin{array}{l}\text { Fibronectin leucine rich } \\
\text { transmembrane protein } 2\end{array}$ & 0.00004 & -4.43384 & 0.00098 \\
\hline SNTB1 & $\begin{array}{l}\text { Syntrophin, b1 (dystrophin-associated protein } \\
\text { A1, 59kDa, basic component } 1 \text { ) }\end{array}$ & 0.00068 & -4.41392 & 0.00236 \\
\hline AIF $1 L$ & Allograft inflammatory factor 1-like & 0.00014 & -8.21928 & 0.00138 \\
\hline$G A L$ & Galanin/GMAP prepropeptide & $<0.00001$ & -11.35750 & 0.00051 \\
\hline$V C A N$ & Versican & 0.00019 & -12.17840 & 0.00152 \\
\hline
\end{tabular}

analysis (Fig. 2B and C) revealed the differential expression profiles of the genes.

Evaluation of the diagnostic potential of differentially expressed genes. To evaluate the diagnostic potential of differentially expressed genes in VCR-resistant MG63 cells, 45 of the downregulated genes (Table II) and 26 of the upregulated genes (Table III) with statistical significance at $\mathrm{P}<0.05$ and a $\geq 4$-fold difference in expression levels between the two cell lines, were selected for further analysis. Based on their putative functions, all genes (Tables II and III) were categorized into subgroups, including transcription factors $(n=2+2)$, enzymes $(n=7+5)$, transporters $(n=2+3)$, transmembrane receptors $(n=1+3)$ and others $(n=33+13)$.

Signaling pathways analysis. To systematically assign putative functions to the differentially expressed genes, bioinformatics analysis was performed. Among the 800 signaling pathways identified by IPA, the major signaling pathways regulated by the differentially expressed genes were enriched in B-cell receptor signaling [including early growth response protein 1, mitogen-activated protein kinases 9 (MAPK9), cell division control protein 42 homolog and protein phosphatase 3 catalytic subunit A], ultraviolet A (UVA)-induced MAPK signaling [including phosphoinositide-3-kinase regulatory subunit 1 , MAPK9 and epidermal growth factor receptor (EGFR)] and Erb-B2 receptor tyrosine kinase 2/3 (ErbB2/3) signaling pathways (including RAS related 2, signal transducer and activator of transcription $5 \mathrm{~B}$ and serine/threonine kinase ATM; Table IV). The first two pathways were predicted to be inhibited, while the last pathway was predicted to be promoted by VCR, suggesting that combination therapy with EGFR inhibitor and VCR may be more effective compared with single-drug therapy. The top enriched pathway was UVA-induced MAPK signaling (Fig. 3A and B), with a z-score of -2.309. The data, together with the predicted signaling pathways, may provide novel insight in determining whether the aberrant expression of these molecules, such as EGFR, may contribute to drug resistance.
RT-qPCR validation of differentially expressed genes. A total of 10 of the differentially expressed genes identified by microarray analysis were selected for further validation using RT-qPCR, including six upregulated genes [multi-drug resistance gene1 $(M D R 1)$, carbonic anhydrase II $(C A I I)$, insulin-like growth factor-II binding protein 1 (IGF2BPI), A-kinase anchor protein 12 (AKAP12), roundabout homolog 1 (ROBO1) and collagen A2 (COL1A2)], and four downregulated genes, including slit guidance ligand 2, death-associated protein kinase 1 (DAPK1), fibronectin leucine rich transmembrane protein 3 (FLRT3) and testin LIM domain protein. As presented in Fig. 4, the expression profiles of the 10 genes were consistent with the microarray data; however, the FC values varied to an extent. RT-qPCR revealed that the expression levels of FLRT3 were increased in MG63/VCR cells, which is in controversy with the microarray data. Thus, 9 of the 10 genes were positively determined by RT-qPCR.

\section{Discussion}

Personalized chemotherapy based on biomarkers may improve the sensitivity to chemotherapy and the clinical outcome of patients with cancer. Thus, investigating the molecular mechanisms underlying drug resistance is essential to develop a personalized chemotherapy regimen and prevent drug resistance during cancer therapy. In the present study, the roles of differentially expressed genes in VCR resistance of osteosarcoma cells were investigated by microarray analysis. Numerous genes determined as differentially expressed in VCR-resistant osteosarcoma cells may also be associated with VCR resistance in the present study, such as MDRl (11), which was upregulated in MG63/VCR cells. Previous studies have indicated that $M D R$ lserves a key role in the proliferation and survival of epithelial and malignant cells during tumorigenesis, as well as in acquired drug resistance $(15,16)$. Few of the differentially expressed genes identified in the present study, including $C A I I$ and $I G F 2 B P 1$, have also been reported to promote cell invasion and drug resistance $(17,18)$; however, some results were in conflict with previous studies. For example, zinc finger E-box binding homeobox 2 and chitinase 
Table III. Genes with upregulated expression of MG63/VCR relative to MG63 cells.

\begin{tabular}{|c|c|c|c|c|}
\hline Gene symbol & Gene name & P-value & Fold change & $\begin{array}{l}\text { False discovery } \\
\text { rate }\end{array}$ \\
\hline \multicolumn{5}{|c|}{ Transcriptional regulators } \\
\hline$R B P M S$ & $\begin{array}{l}\text { RNA-binding protein with multiple } \\
\text { splicing }\end{array}$ & 0.00017 & 4.21538 & 0.00147 \\
\hline$H E Y 1$ & $\begin{array}{l}\text { Hes-related family bHLH transcription } \\
\text { factor with YRPW motif } 1\end{array}$ & 0.00140 & 4.53673 & 0.00336 \\
\hline \multicolumn{5}{|l|}{ Transporters } \\
\hline BET1 & $\begin{array}{l}\text { Bet1 Golgi vesicular membrane } \\
\text { trafficking protein }\end{array}$ & 0.00009 & 5.03427 & 0.00117 \\
\hline$A K A P 12$ & A kinase (PRKA) anchor protein 12 & 0.00011 & 4.74115 & 0.00124 \\
\hline$M D R 1$ & $\begin{array}{l}\text { ATP-binding cassette, sub-family B } \\
\text { (MDR/TAP), member } 1\end{array}$ & $<0.00001$ & 50.25262 & 0.00036 \\
\hline \multicolumn{5}{|c|}{ Transmembrane receptors } \\
\hline$F 3$ & $\begin{array}{l}\text { Coagulation factor III } \\
\text { (thromboplastin, tissue factor) }\end{array}$ & 0.00368 & 6.49217 & 0.00621 \\
\hline TNFRSF19 & $\begin{array}{l}\text { Tumor necrosis factor receptor } \\
\text { superfamily, member } 19\end{array}$ & 0.00037 & 7.31358 & 0.00185 \\
\hline ROBOI & Roundabout guidance receptor 1 & $<0.00001$ & 6.28868 & 0.00035 \\
\hline \multicolumn{5}{|l|}{ Enzymes } \\
\hline GNG11 & $\begin{array}{l}\text { Guanine nucleotide binding } \\
\text { protein (G protein) g11 }\end{array}$ & 0.00001 & 4.43954 & 0.00065 \\
\hline RNF182 & Ring finger protein 182 & $<0.00001$ & 9.08702 & 0.00036 \\
\hline OTUB2 & $\begin{array}{l}\text { OTU deubiquitinase, ubiquitin } \\
\text { aldehyde binding } 2\end{array}$ & 0.00200 & 4.41107 & 0.00410 \\
\hline EPHX4 & Epoxide hydrolase 4 & 0.00024 & 4.63712 & 0.00160 \\
\hline$C A 2$ & carbonic anhydrase II & $<0.00001$ & 10.07676 & 0.00022 \\
\hline \multicolumn{5}{|l|}{ Others } \\
\hline$I G F 2 B P 1$ & $\begin{array}{l}\text { Insulin-like growth factor } 2 \\
\text { mRNA-binding protein I }\end{array}$ & $<0.00001$ & 10.19015 & 0.00051 \\
\hline KIAA1324L & KIAA1324-like & 0.00039 & 4.86219 & 0.00192 \\
\hline$P T P R Q$ & $\begin{array}{l}\text { protein tyrosine phosphatase, } \\
\text { receptor type, } \mathrm{Q}\end{array}$ & 0.00256 & 7.63223 & 0.00479 \\
\hline FAM101B & $\begin{array}{l}\text { family with sequence similarity } \\
101, \text { member B }\end{array}$ & 0.00176 & 4.34868 & 0.00382 \\
\hline$T N N T 1$ & Troponin T type 1 (skeletal, slow) & 0.00070 & 4.17861 & 0.00241 \\
\hline COL1A2 & Collagen, type I, a2 & 0.00173 & 5.21119 & 0.00377 \\
\hline ESRP1 & Epithelial splicing regulatory protein 1 & 0.01391 & 8.18397 & 0.01748 \\
\hline$R B M 48$ & RNA binding motif protein 48 & 0.00151 & 4.44897 & 0.00352 \\
\hline KLHL13 & Kelch-like family member 13 & 0.00022 & 4.27967 & 0.00156 \\
\hline$D S P$ & Desmoplakin & 0.00002 & 7.71674 & 0.00077 \\
\hline$N E F L$ & Neurofilament, light polypeptide & 0.00048 & 4.07517 & 0.00208 \\
\hline AMIGO2 & $\begin{array}{l}\text { Adhesion molecule with Ig-like } \\
\text { domain } 2\end{array}$ & 0.01035 & 4.29618 & 0.01381 \\
\hline AKAP9 & A kinase (PRKA) anchor protein 9 & 0.00038 & 7.09333 & 0.00189 \\
\hline
\end{tabular}

3-like 1 (cartilage glycoprotein-39) were downregulated in MG63/VCR cells compared with MG63 cells, which is inconsistent with other studies $(19,20)$; this may be caused by experimental errors. Different experimental conditions, including sample types, processing methods and sampling time may result in differences in gene expression, which may also be affected by a variety of factors, such as PCR conditions and chip analysis. In addition, there is a lack of data to effectively predict the functions of some of the aberrantly expressed genes at present, including AKAP12, DAPK1 and $R O B O 1$, which may be the potential genes associated with drug resistance; however, further investigation is required. 
A

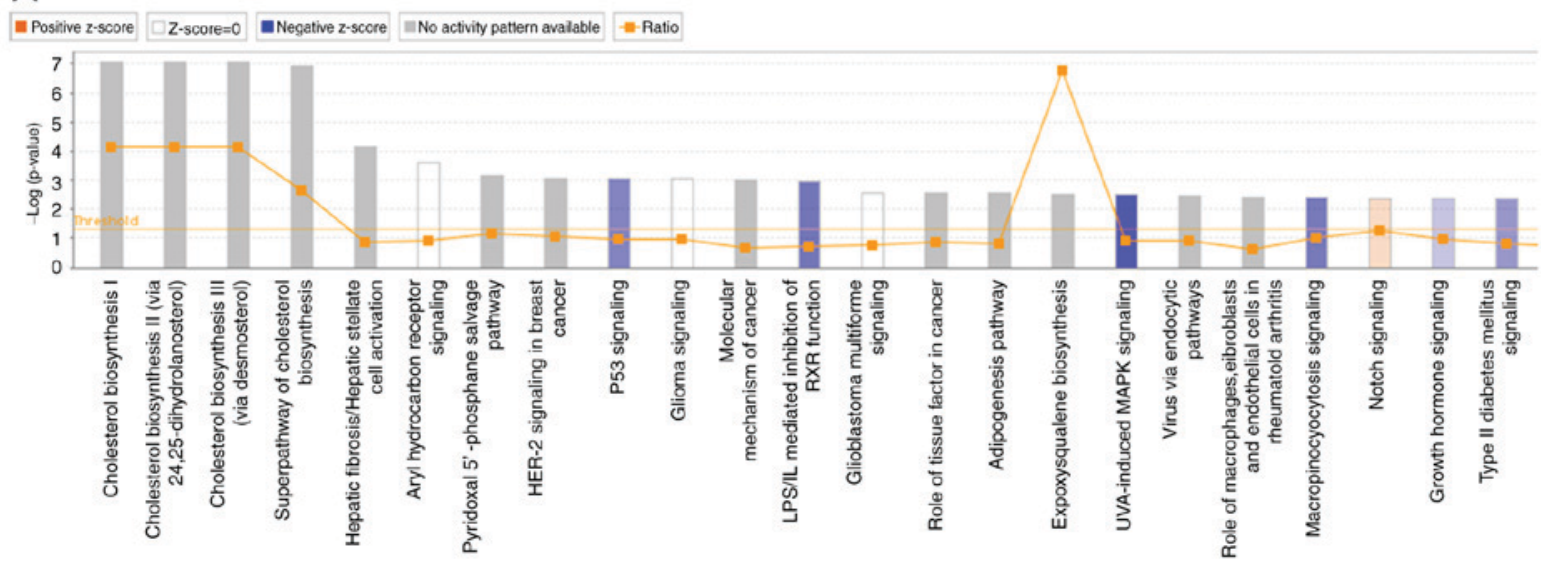

B

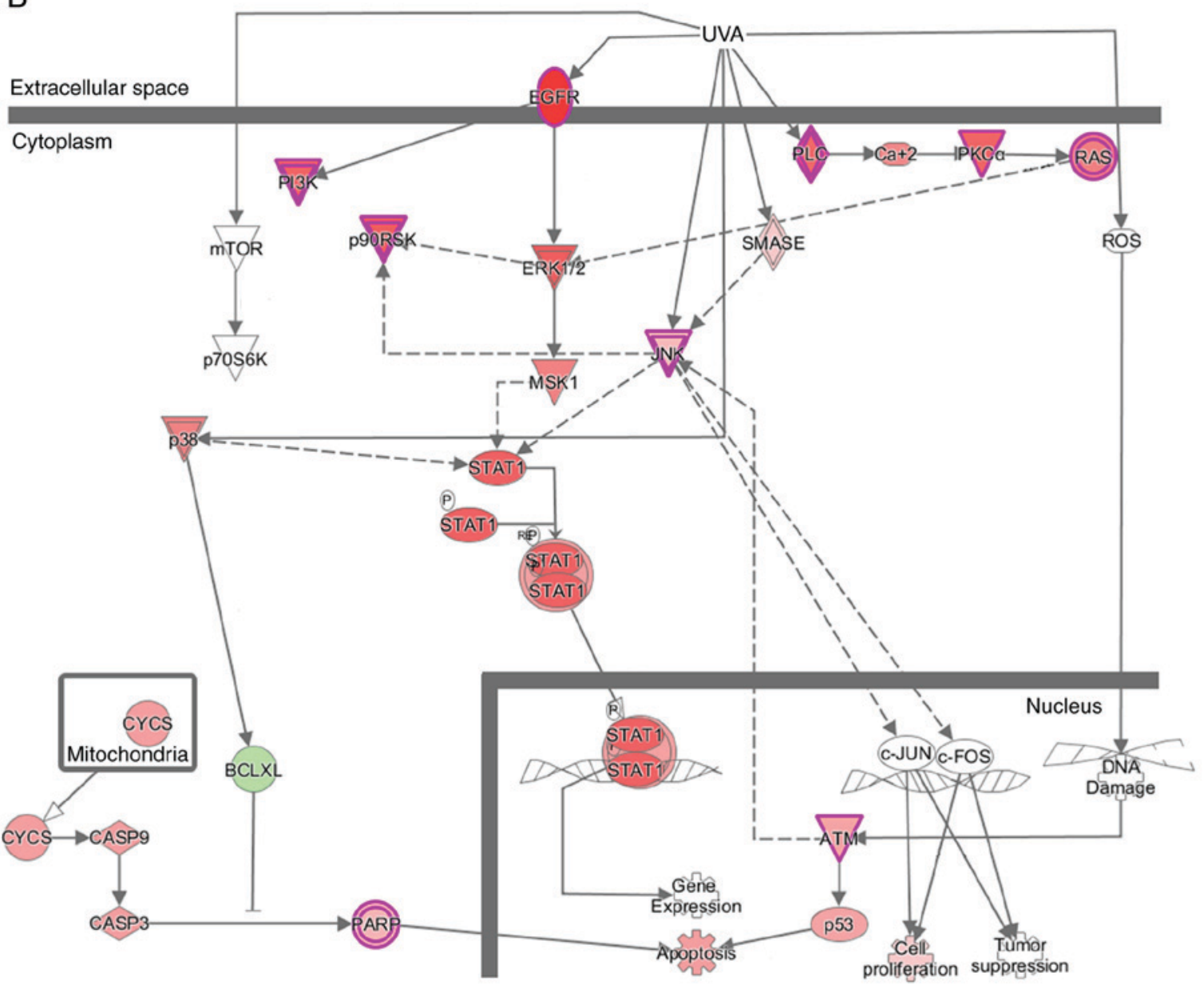

Figure 3. Signaling pathways regulated by differentially expressed genes. (A) Histogram represented enrichment analysis of signaling pathways regulated by differentially expressed genes, ranked by the $\log$ P-value; orange indicates $z>0$ and blue indicates $z<0$. The ratio revealed the number of differentially expressed genes among all the genes involved in the signaling pathways. (B) UVA-induced mitogen-activated protein kinase signaling. Red indicated upregulation; green indicated downregulation; higher intensity presented predicted activation with higher confidence than lower intensity; solid line, direct interaction; dotted line, indirect interaction; UVA, ultraviolet A.

IPA analysis can aid the investigation of novel molecular mechanisms underlying drug resistance. For example, a previous study revealed that the expression levels of COL1A2 and insulin like growth factor 1 receptor $(I G F I R)$, along with the associated pathways, were induced in ovarian cancer cells with topotecan- and paclitaxel-resistance (21). In addition, IGF1R-induced chemoresistance of tumor cells was associated with the signaling pathways involved in the promotion of cell proliferation, inhibition of apoptosis, regulation of ATP-binding cassette transporter proteins and interactions with the extracellular matrix (22); however, other mechanisms underlying drug resistance require further investigation.

Furthermore, signaling pathway analysis revealed that differently expressed genes are mainly enriched in pathways, 
Table IV. Canonical pathways for gene enrichment of differentially expressed genes in MG63/VCR relative to MG63 cells.

\begin{tabular}{|c|c|c|c|c|}
\hline Canonical Pathways & $-\log (\mathrm{P}-\mathrm{value})$ & Ratio & Z-score & Molecules \\
\hline $\begin{array}{l}\text { UVA-induced } \\
\text { MAPK signaling }\end{array}$ & 2.51 & 0.136 & -2.309 & $\begin{array}{l}\text { PLCE1, RRAS2, PIK3R1, ZC3HAV1, MAPK9, } \\
\text { TNKS2, PLCL2, RPS6KA1, PARP14, PRKCA, } \\
\text { ATM, EGFR }\end{array}$ \\
\hline $\begin{array}{l}\text { Role of NFAT in } \\
\text { cardiac hypertrophy }\end{array}$ & 2.33 & 0.106 & -2.065 & $\begin{array}{l}\text { IL6ST, PIK3R1, MAPK9, PLCL2, HDAC6, } \\
\text { CAMK2D, GNG11, PLCE1, RRAS2, MEF2D, } \\
\text { PPP3R1, IGF1R, PRKAG2, PRKCE, MEF2C, } \\
\text { SLC8A1, PPP3CA, ATM, PRKCA }\end{array}$ \\
\hline $\begin{array}{l}\text { LPS-stimulated } \\
\text { MAPK signaling }\end{array}$ & 1.74 & 0.123 & -2.121 & $\begin{array}{l}\text { RRAS2, CDC42, PIK3R1, PRKCE, CD14, } \\
\text { MAPK9, MAP3K5, PRKCA, ATM }\end{array}$ \\
\hline 14-3-3-mediated signaling & 1.56 & 0.103 & -2.530 & $\begin{array}{l}\text { SRPK2, PLCE1, RRAS2, PIK3R1, PRKCE, } \\
\text { MAPK9, PLCL2, BAX, MAP3K5, RPS6KA1, } \\
\text { PRKCA, ATM }\end{array}$ \\
\hline $\mathrm{B}$ cell receptor signaling & 1.24 & 0.086 & -3.207 & $\begin{array}{l}\text { RAP2A, PIK3R1, EGR1, MAPK9, INPPL1, } \\
\text { MALT1, MAP3K5, EBF1, CAMK2D, RRAS2, } \\
\text { CDC42, PPP3R1, MEF2C, PPP3CA, ATM }\end{array}$ \\
\hline HGF signaling & 1.20 & 0.095 & -2.530 & $\begin{array}{l}\text { RRAS2, CDC42, PIK3R1, CDKN1A, PRKCE, } \\
\text { MAPK9, MAP3K5, ITGA4, PRKCA, ATM }\end{array}$ \\
\hline $\begin{array}{l}\text { Role of pattern recognition } \\
\text { receptors in recognition of } \\
\text { bacteria and viruses }\end{array}$ & 1.08 & 0.088 & -2.333 & $\begin{array}{l}\text { PTX3, IL18, C3, PIK3R1, DDX58, CASP1, } \\
\text { PRKCE, MAPK9, EIF2AK2, PRKCA, ATM }\end{array}$ \\
\hline mTOR signaling & 1.03 & 0.080 & -2.138 & $\begin{array}{l}\text { NAPEPLD, ULK1, DDIT4, PIK3R1, FKBP1A, } \\
\text { EIF4E, RRAS2, IRS1, PRKAG2, PRKAA1, } \\
\text { PRKCE, RPS6KA1, ATM, RPS14, PRKCA }\end{array}$ \\
\hline Endothelin-1 signaling & 1.03 & 0.081 & -2.111 & $\begin{array}{l}\text { NAPEPLD, PIK3R1, MAPK9, PLCL2, } \\
\text { RRAS2, PLCE1, GNAO1, CASP1, RARRES3, } \\
\text { PRKCE, ECE1, CASP7, ATM, PRKCA }\end{array}$ \\
\hline $\begin{array}{l}\text { Signaling by Rho } \\
\text { family GTPases }\end{array}$ & 1.02 & 0.077 & -2.000 & $\begin{array}{l}\text { PIK3R1, WASF3, CDH6, MAPK9, MYLK, } \\
\text { CDH11, LIMK1, CDH2, ARPC1A, GNG11, } \\
\text { CDH5, CDC42, EZR, GNAO1, ARHGEF18, } \\
\text { ARHGEF9, ATM, ITGA4 }\end{array}$ \\
\hline HMGB1 signaling & 0.90 & 0.083 & -2.530 & $\begin{array}{l}\text { IL18, ICAM1, RRAS2, CCL2, CDC42, } \\
\text { PIK3R1, MAPK9, TNFRSF11B, ATM, PLAT }\end{array}$ \\
\hline $\begin{array}{l}\text { Leukocyte } \\
\text { extravasation signaling }\end{array}$ & 0.88 & 0.076 & -2.111 & $\begin{array}{l}\text { ICAM1, PIK3R1, THY1, MAPK9, MLLT4, } \\
\text { CDH5, CDC42, JAM3, EZR, CD44, PRKCE, } \\
\text { ATM, PRKCA, ITGA4, CTNND1 }\end{array}$ \\
\hline CNTF signaling & 0.81 & 0.096 & -2.236 & IL6ST, RRAS2, PIK3R1, RPS6KA1, ATM \\
\hline $\begin{array}{l}\text { Role of NANOG in } \\
\text { mammalian embryonic } \\
\text { stem cell pluripotency }\end{array}$ & 0.80 & 0.081 & -2.000 & $\begin{array}{l}\text { IL6ST, RRAS2, WNT3, PIK3R1, } \\
\text { WNT2B, SMAD4, FZD1, BMP5, ATM }\end{array}$ \\
\hline $\begin{array}{l}\text { Fc } \gamma \text { RIIB signaling } \\
\text { in B lymphocytes }\end{array}$ & 0.73 & 0.098 & -2.000 & RRAS2, PIK3R1, MAPK9, ATM \\
\hline NGF signaling & 0.63 & 0.075 & -2.828 & $\begin{array}{l}\text { RRAS2, CDC42, PIK3R1, MAPK9, BAX, } \\
\text { MAP3K5, RPS6KA1, ATM }\end{array}$ \\
\hline $\begin{array}{l}\text { CD28 signaling } \\
\text { in } \mathrm{T} \text { helper cells }\end{array}$ & 0.49 & 0.068 & -2.828 & $\begin{array}{l}\text { ARPC1A, CDC42, PIK3R1, PPP3R1, MAPK9, } \\
\text { MALT1, PPP3CA, ATM }\end{array}$ \\
\hline $\begin{array}{l}\text { RANK signaling } \\
\text { in osteoclasts }\end{array}$ & 0.45 & 0.068 & -2.449 & $\begin{array}{l}\text { PIK3R1, PPP3R1, MAPK9, MAP3K5, } \\
\text { PPP3CA, ATM }\end{array}$ \\
\hline ErbB2-ErbB3 signaling & 0.42 & 0.070 & 2.000 & RRAS2, PIK3R1, STAT5B, ATM \\
\hline Insulin receptor signaling & 0.36 & 0.061 & -2.121 & $\begin{array}{l}\text { RRAS2, IRS1, PIK3R1, PRKAG2, IRS2, } \\
\text { INPPL1, EIF4E, ATM }\end{array}$ \\
\hline $\begin{array}{l}\text { Renal cell carcinoma } \\
\text { signaling }\end{array}$ & 0.26 & 0.056 & -2.000 & RRAS2, CDC42, PIK3R1, ATM \\
\hline
\end{tabular}




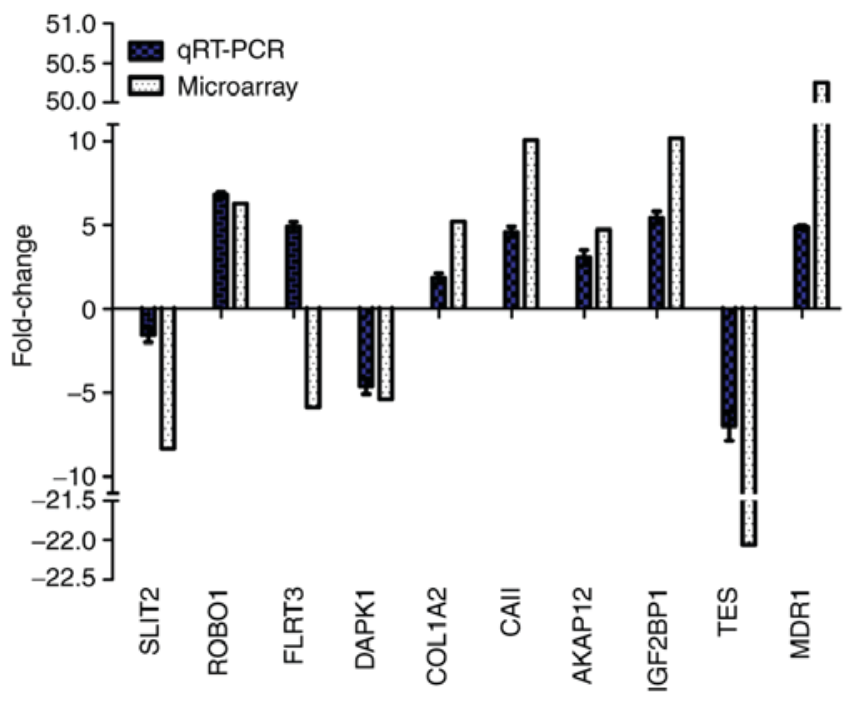

Figure 4. RT-qPCR validation of the microarray results for ten selected genes. Relative fold changes as determined by RT-qPCR are plotted against the microarray data. AKAP12, A-kinase anchor protein 12; CAII, carbonic anhydrase II; COL1A2, collagen A2; DAPK1, death-associated protein kinase 1; FLRT3, fibronectin leucine rich transmembrane protein 3 IGF2BP1, insulin-like growth factor-II binding protein 1; MDR1, multi-drug resistance gene1; ROBO1, roundabout homolog 1; RT-qPCR, reverse transcription-quantitative polymerase chain reaction; SLIT2, slit guidance ligand 2; TES, testin LIM domain protein.

including B cell receptor signaling, UVA-induced MAPK signaling and ErbB2-ErbB3 signaling, which were previously associated with drug resistance (23-25). For instance, B-cell receptor signaling was reported as an essential mediator of cytoskeletal reorganization, integrin clustering and environmental-mediated drug resistance (23). A recent study revealed that the steroidal lactone withaferin A may serve as a low-toxicity addition to ERBB2-targeted therapeutics, particularly when ERBB3 induced resistance or reduced overall sensitivity (24). Several studies have indicated that numerous proteins are involved in UVA-induced MAPK signaling, such as EGFR ( $\mathrm{P}=0.003473, \mathrm{FC}=1.95397)$, which was upregulated in MG63/VCR cells and maybe a key regulator in the pathways associated with VCR resistance $(25,26)$. EGFR is a transmembrane tyrosine kinase receptor, and is one of the most extensively studied MDR-associated receptors (25). Inhibition of the EGFR/HER2 signaling pathway, particularly the activity of downstream PI3K, induced a more favorable milieu for tumor immunotherapy (26). While the UVA-induced MAPK signaling pathway was downregulated in MG63-VCR cells, EGFR was upregulated; however, the effects of this pathway on drug resistance remain unknown.

In conclusion, differentially expressed genes were identified between MG63/VCR and MG63 cells in the present study. These results revealed the potential functions of these genes, providing novel insight into their roles in drug resistance and associated pathways, which may aid the identification of novel potential targets for the treatment of osteosarcoma.

\section{Acknowledgements}

Not applicable.

\section{Funding}

The present study was supported by the International Cooperation of Jilin Provincial Science \& Technology Department (grant no. 20150101175JC) and the National Natural Science Foundation of China (grant nos. 81172000 and 30772488).

\section{Availability of data and materials}

The datasets used or analysed during the current study are available from the corresponding author on reasonable request.

\section{Authors' contributions}

YW was the person in charge of this project, responsible for overall planning and specific project implementation. YW and $\mathrm{RC}$ conceived and designed the study. L-HH has provided technical support and experimental guidance in the construction of multidrug resistant cell sublines and is responsible for monitoring the stability of multidrug resistant cells. RC, Y-YG, $\mathrm{J}-\mathrm{ZY}$ performed the experiments. $\mathrm{YW}$ and $\mathrm{RC}$ wrote the paper. RC, Y-YG, J-ZY, L-HH and YW reviewed and edited the manuscript. All authors read and approved the manuscript.

\section{Ethics approval and consent to participate}

Not applicable.

\section{Patient consent for publication}

Not applicable.

\section{Competing interests}

The authors declare that they have no competing interests.

\section{References}

1. Cai S, Zhang T, Zhang D, Qiu G and Liu Y: Volume-sensitive chloride channels are involved in cisplatin treatment of osteosarcoma. Mol Med Rep 11: 2465-2470, 2015.

2. Zhang Y, Zhang L, Zhang G, Li S, Duan J, Cheng J, Ding G, Zhou C, Zhang J, Luo P, et al: Osteosarcoma metastasis: Prospective role of ezrin. Tumor Biol 35: 5055-5059, 2014.

3. Luetke A, Meyers PA, Lewis I and Juergens H: Osteosarcoma treatment-where do we stand? A state of the art review. Cancer Treat Rev 40: 523-532, 2014.

4. Wang Y and Teng JS: Increased multi-drug resistance and reduced apoptosis in osteosarcoma side population cells are crucial factors for tumor recurrence. Exp Ther Med 12: 81-86, 2016.

5. Wang $X$, Zheng $H$, Shou $T$, Tang $C$, Miao $K$ and Wang $P$ : Effectiveness of multi-drug regimen chemotherapy treatment in osteosarcoma patients: A network meta-analysis of randomized controlled trials. J Orthop Surg Res 12: 52, 2017.

6. Hattinger CM, Pasello M, Ferrari S, Picci P and Serra M: Emerging drugs for high-grade osteosarcoma. Expert Opin Emerg Drugs 15: 615-634, 2010.

7. Chou AJ and Gorlick R: Chemotherapy resistance in osteosarcoma: Current challenges and future directions. Expert Rev Anticancer Ther 6: 1075-1085, 2016.

8. Ottaviani G and Jaffe N: The epidemiology of osteosarcoma. Cancer Treat Res 152: 3-13, 2009.

9. Brasseur K, Gévry N and Asselin E: Chemoresistance and targeted therapies in ovarian and endometrial cancers. Oncotarget 8: 4008-4042, 2017. 
10. Lu C and Shervington A: Chemoresistance in gliomas. Mol Cell Biochem 312: 71-80, 2008.

11. Yang JZ, Ma SR, Rong XL, Zhu MJ, Ji QY, Meng LJ, Gao YY, Yang YD and Wang Y: Characterization of multidrug-resistant osteosarcoma sublines and the molecular mechanisms of resistance. Mol Med Rep 14: 3269-3276, 2016.

12. Felciano RM, Bavari S, Richards DR, Billaud JN, Warren T, Panchal R and Krämer A: Predictive systems biology approach to broad-spectrum, host-directed drug target discovery in infectious diseases. Pac Symp Biocomput: 17-28, 2013.

13. Calvano SE, Xiao W, Richards DR, Felciano RM, Baker HV, Cho RJ, Chen RO, Brownstein BH, Cobb JP, Tschoeke SK, et al: A network-based analysis of systemic inflammation in humans. Nature 437: 1032-1037, 2013

14. Livak KJ and Schmittgen TD: Analysis of relative gene expression data using real-time quantitative PCR and the 2(-Delta Delta C(T)) method. Methods 25: 402-408, 2001.

15. Wang Z, Xia Q, Cui J, Diao Y and Li J: Reversion of P-glycoprotein-mediated multidrug resistance by diallyl trisulfide in a human osteosarcoma cell line. Oncol Rep 31: 2720-2726, 2014.

16. Tahara T, Arisawa T, Shibata T, Hirata I and Nakano H: Multi-drug resistance 1 polymorphism is associated with reduced risk of gastric cancer in the Japanese population. J Gastroenterol Hepatol 22: 1678-1682, 2007.

17. Zhou R, Huang W, Yao Y, Wang Y, Li Z, Shao B, Zhong J, Tang M, Liang S, Zhao X, et al: CA II, a potential biomarker by proteomic analysis, exerts significant inhibitory effect on the growth of colorectal cancer cells. Int J Oncol 43: 611-621, 2013.

18. Faye MD, Beug ST, Graber TE, Earl N, Xiang X, Wild B, Langlois S, Michaud J, Cowan KN, Korneluk RG and Holcik M: IGF2BP1 controls cell death and drug resistance in rhabdomyosarcomas by regulating translation of cIAP1. Oncogene 34: $1532-1541,2015$.
19. Xie XQ, Zhao QH, Wang $\mathrm{H}$ and Gu KS: Dysregulation of mRNA profile in cisplatin-resistant gastric cancer cell line SGC7901. World J Gastroentero 23: 1189-1202, 2017.

20. Chiang YC, Lin HW, Chang CF, Chang MC, Fu CF, Chen TC, Hsieh SF, Chen CA and Cheng WF: Overexpression of CHI3L1 is associated with chemoresistance and poor outcome of epithelial ovarian carcinoma. Oncotarget 6: 39740-39755, 2015.

21. Januchowski R, Świerczewska M, Sterzyńska K, Wojtowicz K, Nowicki $\mathrm{M}$ and Zabel M: Increased expression of several collagen genes is associated with drug resistance in ovarian cancer cell lines. J Cancer 7: 1295-1310, 2016.

22. Yuan J, Y in Z, Tao K, Wang G and Gao J: Function of insulin-like growth factor 1 receptor in cancer resistance to chemotherapy. Oncol Lett 15: 41-47, 2018.

23. Spaargaren M, Beuling EA, Rurup ML, Meijer HP, Klok MD, Middendorp S, Hendriks RW and Pals ST: The B cell antigen receptor controls integrin activity through Btk and PLCgamma2. J Exp Med 198: 1539-1550, 2003

24. Liu W, Barnette AR, Andreansky S and Landgraf R: ERBB2 overexpression establishes ERBB3-dependent hypersensitivity of breast cancer cells to withaferin A. Mol Cancer Ther 15: 2750-2757, 2016.

25. Ekstrand AJ, James CD, Cavenee WK, Seliger B, Pettersson RF and Collins VP: Genes for epidermal growth factor receptor, transforming growth factor, and epidermal growth factor and their expression in human gliomas in vivo. Cancer Res 51: 2164-2172, 1991.

26. Suh KJ, Sung JH, Kim JW, Han SH, Lee HS, Min A, Kang MH, Kim JE, Kim JW, Kim SH, et al: EGFR or HER2 inhibition modulates the tumor microenvironment by suppression of PD-L1 and cytokines release. Oncotarget 8: 63901-63910, 2017.

(i) $\Theta$ This work is licensed under a Creative Commons Attribution-NonCommercial-NoDerivatives 4.0 International (CC BY-NC-ND 4.0) License. 